Mem. Inst. Oswaldo Cruz, Rio de Janeiro, Vol. 81(2):171-184, abr./jun. 1986

\title{
ALTERAÇŌES BIOMORFOGÊNICAS CAUSADAS PELA APLICAÇĀO DE PRECOCENO II EM NINFAS DE TRIATOMA INFESTANS (KLUG, 1834) (HEMIPTERA, REDUVIIDAE, TRIATOMINAE)
}

\author{
JOSÉ JURBERG, JANE MARGARET COSTA, TERESA CRISTINA M. GONÇALVES, \\ ELOI GARCIA \& PATRICIA DE AZAMBUJA*
}

O precoceno II aplicado topicamente em ninfas de 49 estádio, nas dosagens de 200, 300 e $400 \mu \mathrm{g} / 1 \mu \mathrm{l}$ de acetona, proporcionou o aparecimento de adultóides, em diferentes percentagens com as seguintes caracteristicas: tegumento alterado, aparelho bucal deformado, asas braquipteras, tarsos trimeros, ocelos evidentes e genitália externa com estruturas desenvolvidas e deformadas; genitália in terna em estágio in termediário entre ninfas de 40 e 50 estádios.

Os adultóides apresentaram um periodo de sobrevivência inversamente proporcional à dosagem aplicada, variando de 3 a 22 dias, näo tendo se alimentado devido as alteraçōes.

Palavras-chave: precoceno II - ninfas de Triatoma infestans - alteraçöes morfológicas

- al teraçôes biológicas

Desde a descoberta do precoceno I e II (Bowers, 1976; Bowers et al., 1976) vários trabalhos têm sido publicados mostrando a ação destes compostos em insetos (Bowers, 1981; Bowers, 1982a,b). Em geral, estas investigaçōes demonstram que os precocenos inibem o crescimento do corpus allatum (Bowers, 1976; Bowers et al., 1976; Bowers \& Martinez-Pardo, 1977; Pener, Orshan \& De Wilde, 1978; Unnithan \& Nair, 1979) por induzirem atrofia em células (Unnithan, Nair \& Bowers, 1977; Liechtly \& Sedlak, 1978; Schooneveld, 1979; Azambuja, Garcia \& Furtado, 1981). A degeneração do corpus allatum in vivo (Bowers, 1976; Bowers et al., 1976; Bowers, 1981; Azambuja, Garcia \& Furtado, 1981) e in vitro (Pratt \& Bowers, 1977; Bowers \& Fedlanfer, 1982) interfere na produçāo do hormônio juvenil. Os estudos sobre o metabolismo e modo de ação dos precocenos sugerem que estes compostos sofrem uma ativação oxidativa por enzimas do tipo mono-oxigenases, formando compostos altamente reativos, os quais reagem com componentes celulares do corpus allatum causando a destruição desta glândula (Pratt et al., 1980; Bowers et al., 1982). Assim, os fenômenos biológicos dependentes do hormônio juvenil, principalmente, a metamorfose e o crescimento ovariano, nos insetos sensíveis, ficam drasticamente prejudicados.

Os efeitos fisiológicos e morfológicos dos precocenos em triatomíneos foram demonstrados por Tarrant \& Cupp (1978), Azambuja, Garcia \& Ribeiro (1981), Azambuja et al. (1982), Jurberg et al. (1984) e Garcia, Azambuja \& Bowers (1984) em Rhodnius prolixus; Jurberg, Gonçalves \& Oliveira Filho (1982) em Panstrongylus megistus; Tarrant, Cupp \& Bowers (1982) em Triatoma dimidiata.

O presente trabalho tem como objetivo estudar detalhadamente em Triatoma infestans o principal transmissor da doença de Chagas no Brasil, a morfologia externa e interna dos adultóides, bem como alguns aspectos de sua biologia, após o tratamento tópico com precoceno II, visando o encontro de substâncias específicas atóxicas ao meio ambiente no controle de insetos.

\section{MATERIAL E MÉTODOS}

Insetos: utilizaram-se 50 ninfas de 4 \% estádio, obtidas de uma das colônias mantidas com sangue de pombo no Departamento de Entomologia do Instituto Oswaldo Cruz. Os insetos foram selecionados imediatamente após a terceira ecdise e mantidos sem alimentação por 20 dias, a fím de assegurar um repasto farto e homogêneo para o grupo.

As ninfas foram pesadas antes $(\overrightarrow{\mathrm{X}} \pm$ E.P. $=37,8 \pm 2,5 \mathrm{mg})$ e após a alimentaçāo com sangue de pombo $(\overrightarrow{\mathrm{X}} \pm$ E.P. $=210,25 \pm 10,16 \mathrm{mg})$.

Trabalho realizado com auxilio do CNPq (PIDE V) e apresentado no IX Congresso da Sociedade Brasileira de Parasitologia - Fortaleza - Agosto de 1985.

Instituto Oswaldo Cruz, Departamento de Entomologia, Caixa Postal 926, 20001 Rio de Janeiro, RJ, Brasil. Auxílio do FIPEC - Proc. no 1.1664.0.

*Departamento de Biologia Geral, UFF, Niterói, RJ, Brasil.

Recebido para publicaçāo em 17 de setembro e aceito em 19 de novembro de 1985 . 
Tratamento: o tratamento tópico da substância foi feito com auxílio de uma microsseringa nos tergitos abdominais de 41 ninfas que estavam bem alimentadas. $O$ precoceno II foi diluído em acetona, nas concentraçōes de $100,200,300$ e $400 \mu \mathrm{g} / 1 \mu \mathrm{l}$, sendo aplicado $1 \mu \mathrm{l}$ em cada inseto.

Foram utilizados os seguintes lotes para cada dose:

10 insetos - $1 \mu$ l de acetona (controle)

5 insetos $-100 \mu \mathrm{g}$ de precoceno II $/ 1 \mu \mathrm{l}$ acetona

6 insetos $-200 \mu \mathrm{g}$ de precoceno II $/ 1 \mu$ l acetona

10 insetos $-300 \mu \mathrm{g}$ de precoceno II $/ 1 \mu \mathrm{l}$ acetona

10 inse tos $-400 \mu \mathrm{g}$ de precoceno II $/ 1 \mu \mathrm{l}$ acetona e $70 \%$ U.R.

$O$ material foi mantido durante seis meses em estufa B.O.D. - modelo 347 - a $28^{\circ} \pm 1{ }^{\circ} \mathrm{C}$

Para a observação morfológica da genitália interna de machos, os exemplares foram dissecados em soro fisiológico para insetos $(0,7 \% \mathrm{NaCl}$ e $0,3 \% \mathrm{KCl})$. Após a remoção dos testículos, a membrana foi retirada e os tubos testiculares em evidência foram desenhados e medidos com auxílio de um curvímetro.

\section{RESULTADOS}

Morfologia externa - Tanto no grupo controle quanto no grupo no qual foram aplicados $100 \mu \mathrm{g} / 1 \mu \mathrm{l}$ de precoceno II, diluído em acetona, não se observou qualquer alteração morfológica aparente.

Os outros grupos que receberam 200,300 e $400 \mu \mathrm{g} / 1 \mu \mathrm{l}$ de precoceno II diluído em acetona, produziram adultóides com deformaçōes morfológicas que não diferiram significativamente entre as dosagens. Estas características foram analisadas comparativamente com ninfas de 50 estádio e adultos normais (Figs. 1 e 2) de nossa criação e também segundo as descriçōes de Lent \& Jurberg (1978) e Lent \& Wygodzinsky (1979).

De um modo geral, encontraram-se os mesmos tipos de deformações observadas em Rhodnius prolixus registradas no trabalho de Jurberg et al. (1984).
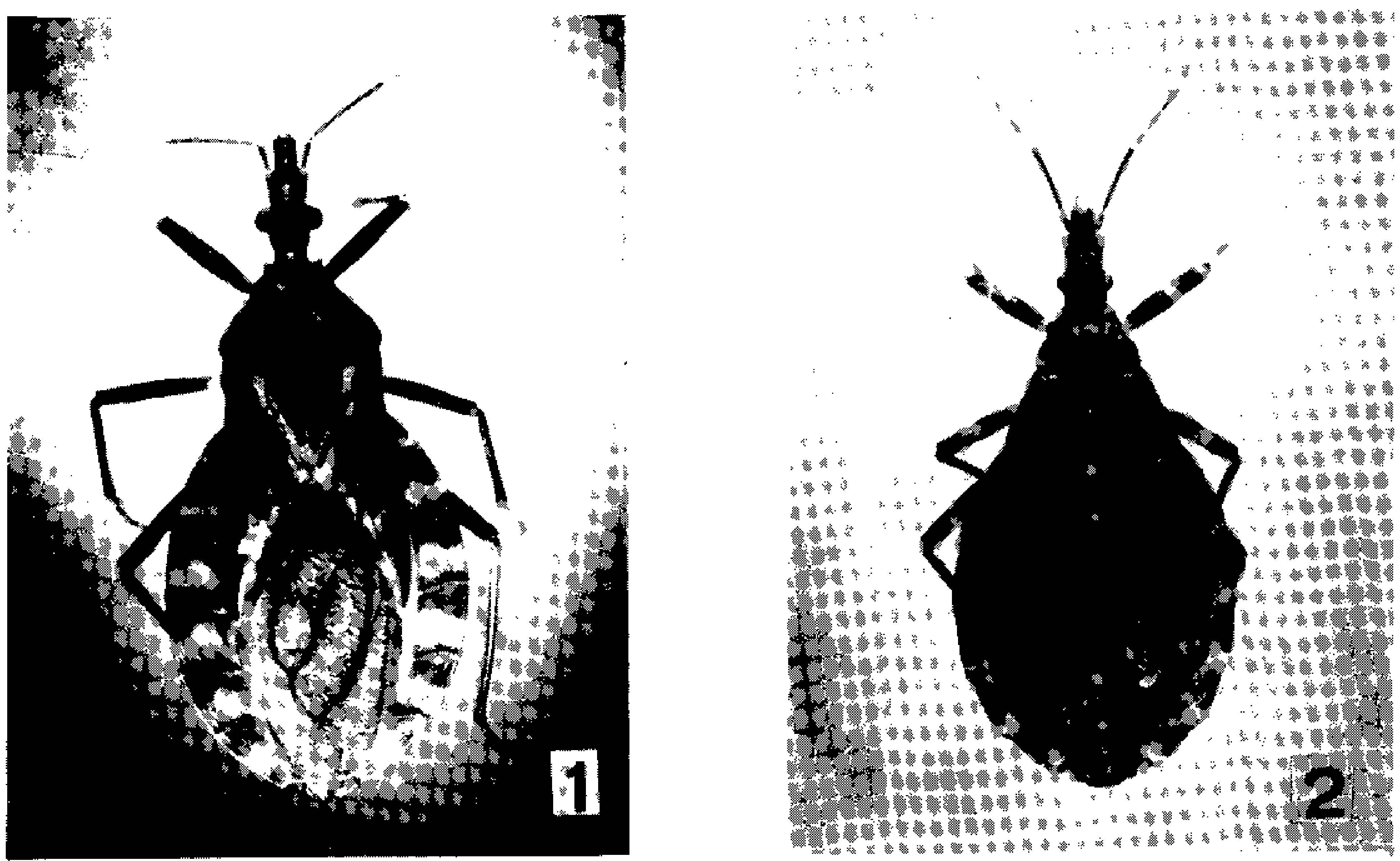

Fig. 1: adulto normal. Fig. 2 : ninfa de 5 o estádio normal. 
Os adultóides apresentaram as seguintes características: em alguns exemplares, a ecdise não se processou totalmente, ficando a cabeça curvada para a face ventral e o corpo parcialmente envolvido pela exúvia, sobretudo as extremidades (rostro, patas e regiāo posterior do abdômen) (Fig. 3); tegmento de todo corpo glabro, sem tubérculos setíferos que são evidentes em ninfas de 50 estádio (Figs. 4 e 5); rostro algumas vezes com estiletes maxilares e mandibulares retorcidos e fora do canal labial; ocelos desenvolvidos; número de artículos tarsais variando entre 2 e 3 , inclusive na mesma dosagem; protórax com lobo anterior e posterior separados; mesotórax representado pelo escutelo bem desenvolvido; asas anteriores braquípteras, com cório e membrana distintos, atingindo a região anterior do 4 o segmento abdominal; asas posteriores membranosas, enrugadas, atingindo o 29 segmento abdominal (Fig. 6).

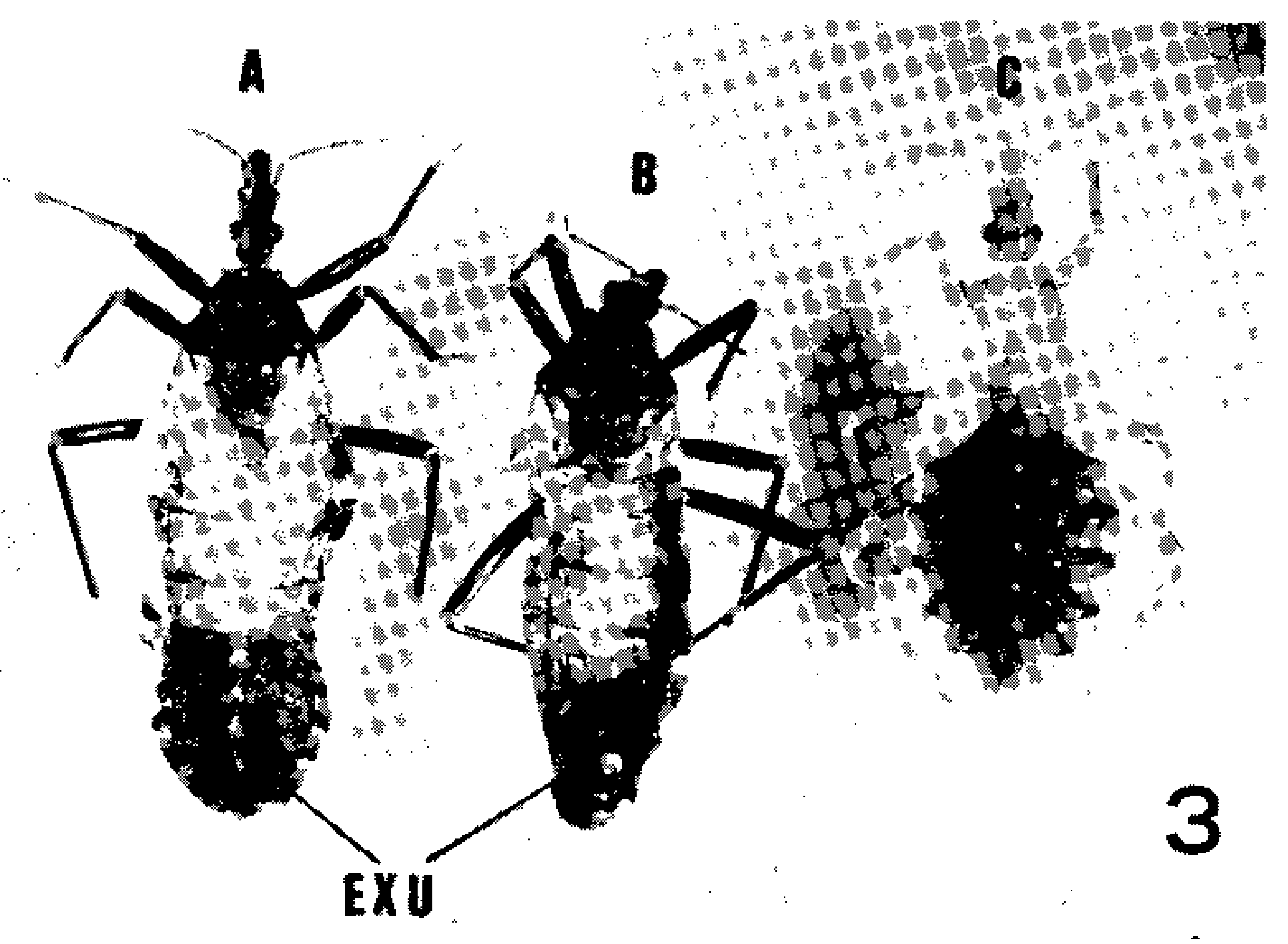

Fig. 3a: adultóide resultante da aplicaçāo de $300 \mu \mathrm{g}$ com exúvia presa à extremidade posterior do abdômen. Fig. $3 \mathrm{~b}$ : idem com $400 \mu \mathrm{g}$. Fig. $3 \mathrm{c}$ : ninfa de 5 o estádio normal (EXU - exúvia).

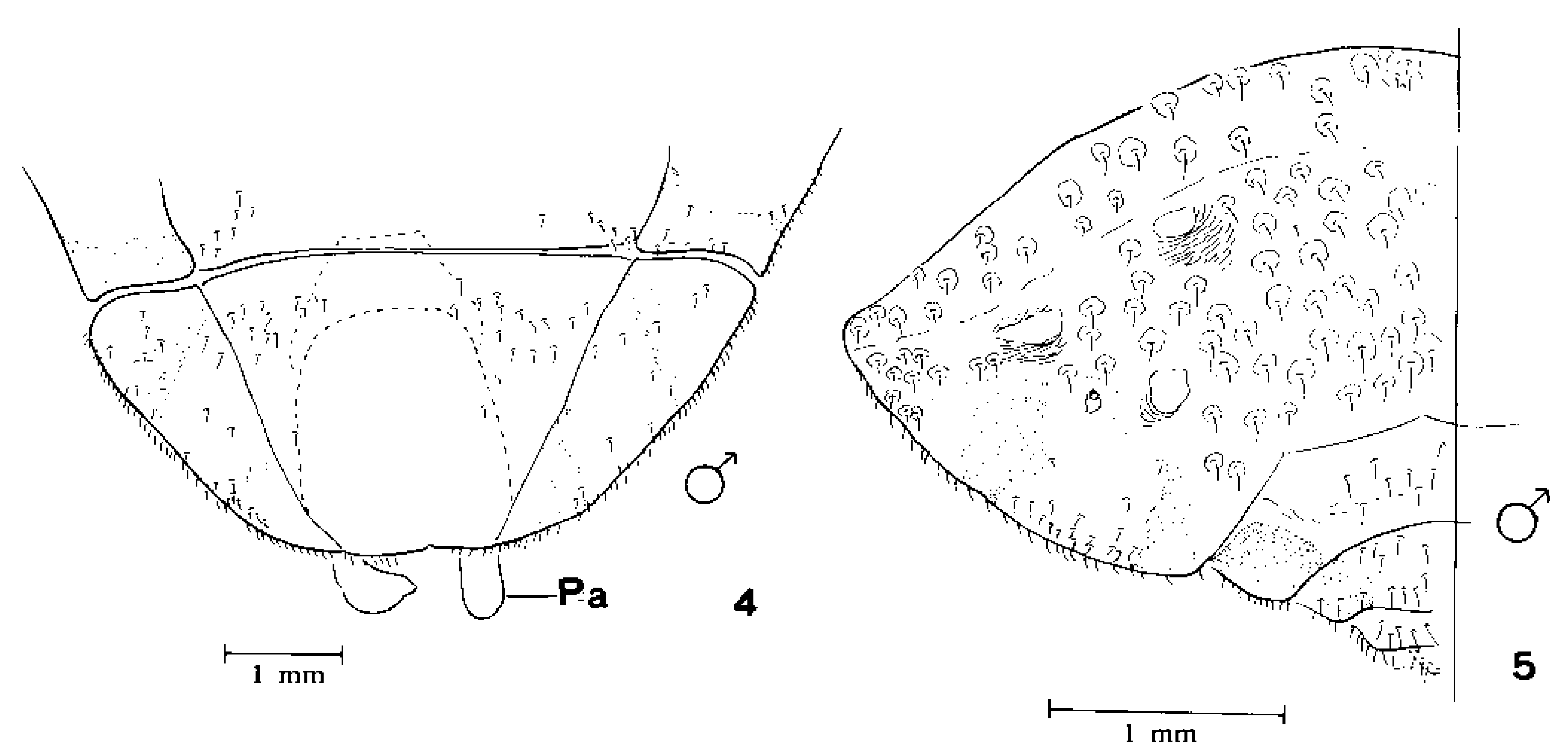

Fig. 4: extremidade posterior do abdômen de um adultóide resultante da aplicação de $200 \mu \mathrm{g}$, vista dorsal. Fig. 5: lado esquerdo da extremidade posterior do abdômen de uma ninfa đe 50 ố estádio normal, vista dorsal ( $\mathrm{Pa}$ - parâmero). 


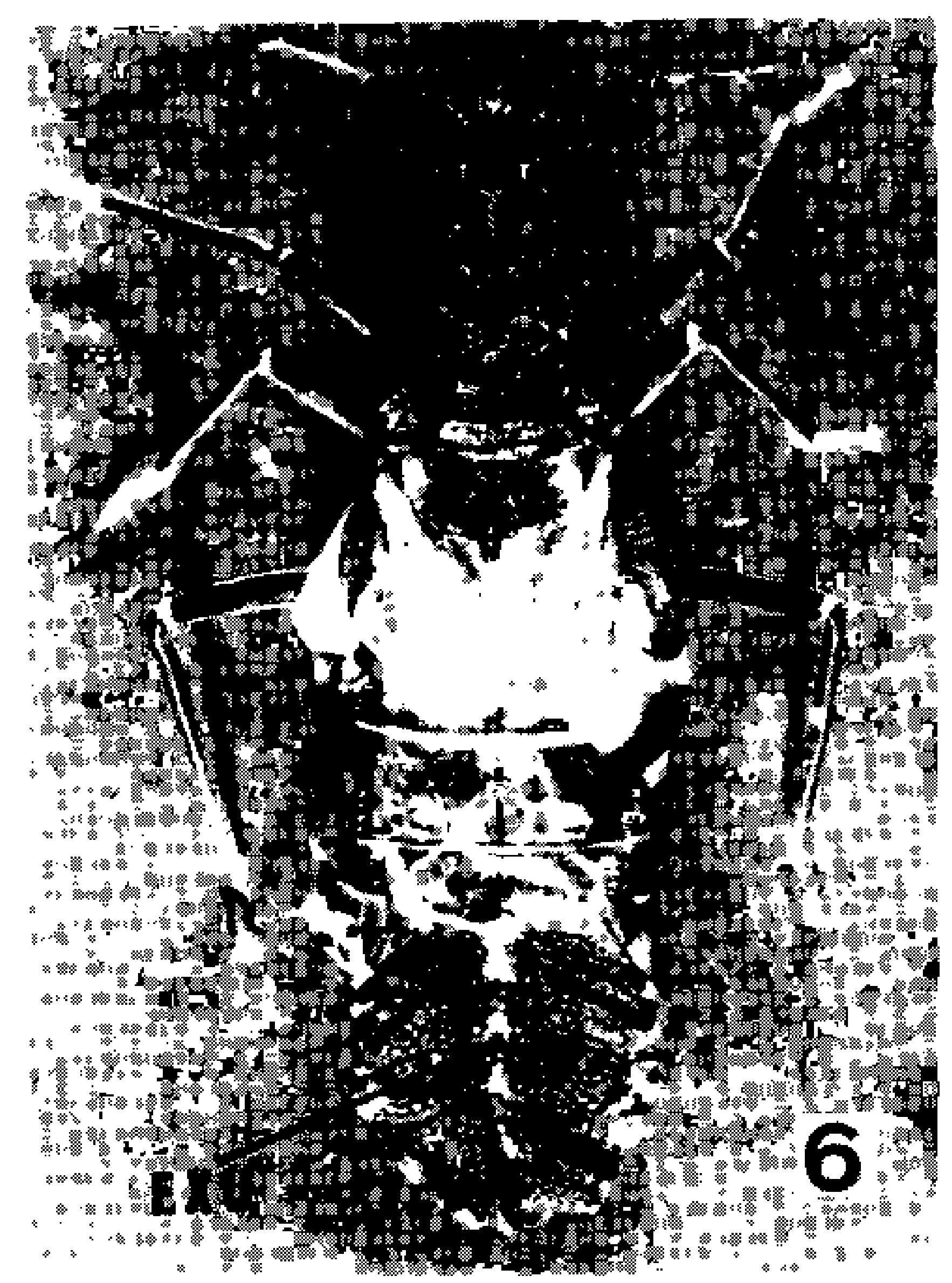

Fig. 6: adultóide resultante da aplicação de $300 \mu \mathrm{g}$ com exúvia presa à extremidade posterior do abdômen (l:XU - exúvia).

Genitália extema - As genitálias dos adultóides tan to machos quanto fềmeas apresentaram-se incompletas e deformadas, com esboço das estruturas fálicas e placas genitais respectivamente, não estando as deformações correlacionadas com a maior ou menor dosagem aplicada.

Machos: nas dosagens de 200.300 e $400 \mu \mathrm{g} / 1 \mu \mathrm{l}$ o pigóforo mostrou-se com pouca variaçāo, porém o processo mediano do pigóforo (PrP) era acuminado, rombo ou sem projeçāo (Figs. 7,8 e 9). A genitália apresentou-se como um aglomerado, reunindo parâmeros e falo, ambos atrofiados: os primeiros, com tamanho variável e o segundo com esboço do aparelho articular (Apb) e um delineamento do edeago (Ae) mostrando que tal deformaçăo impossibilitaria a realização da cópula (Figs. 10, 11, 12 e 13).

Os adultos normais apresentam dentro do pigóforo (IX) o órgão intromitente constituído do aparelho articular ( $\mathrm{Apb}$ ) e um edeago ( $\mathrm{Ae})$. O primeiro é formado pelas seguintes estruturas: ponte basal ( $\mathrm{PB})$, processo capitato ( $\mathrm{PrC})$, conectivo dorsal $(\mathrm{Cd})$, placa basal ( $\mathrm{Plb}$ ), processo gonoporo (PrG) e extensāo mediana da placa basal (EPlb). O segundo formado por algumas estruturas como o falosoma $(\mathrm{Ph})$, suporte do falosoma ( $\mathrm{Sph}$ ) e o processo do endosoma ( $\mathrm{PrEn}$ ) (Fig. 14). Como órgãos acessórios são encontrados $1+1$ parâmeros (Pa) (Fig. 15) e o Processo mediano do pigóforo (PrP) (Fig. 16).

As ninfas de 5 o estádio normais com características de macho apresentam ventralmente na margem posterior do 90 segmento uma dobra interna, medianamente ponteaguda, quando vistos diafanizados (Fig. 17).

Fêmeas: nas ninfas de 49 estádio, que foram tratadas com $300 \mathfrak{c} 400 \mu \mathrm{g}$ de precoceno II. o conjunto de placas genitais apresentou-se completo, porém atrofiado, com discretas diferenças entre o tamanho e a forma dos gonocoxitos (Gc) e gonapófises (G) (Figs. 18 e 19).

Não se obtiveram adultóides fêmeas na dosagem de $200 \mu \mathrm{g}$.

Em ninfas normais de 5 o estádio, com caracteristicas de fêmea, observaram-se, em vista ventral, placas arredondadas, embutidas em áreas membranosas do 89 e 90 segmentos (Fig. 20), que nos adultos resultaram nos dois pares de placas genitais: gonocóxitos ( $\mathrm{Gc8}$ e Gc9) e gonapófises (G8 e G9) (Figs. 21, 22 e 23).

Genitália intema - Nos triatomíneos os testículos (Fig. 24) são constituídos por sete tubos testiculares. cujo comprimento varia para cada gênero (Barth, 1956: Silva \& Schreiber, 1969).

Em Triatoma spp. existem dois tubos longos, dois médios e três curtos. Nas fases de ninfa. a partir do 4 Q estádio, estes são pequenos e crescem proporcionalmente a cada muda, até chegar à fase adulta, quando atingem seu comprimento máximo (Tab. I). 

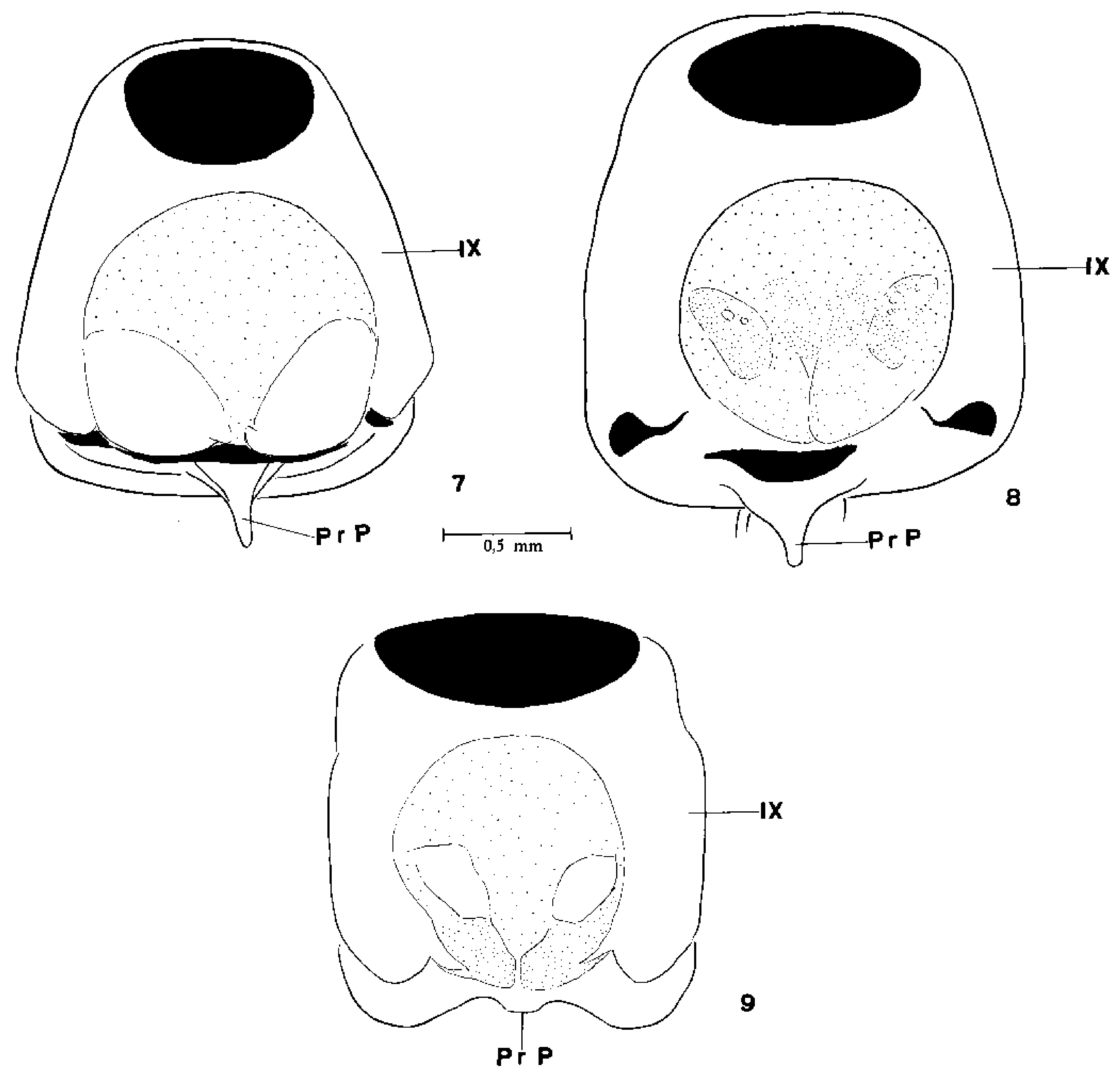

Pigóforo vista dorsal, mostrando o processo mediano do pigóforo. Fig. 7: com formato acuminado $(400 \mu \mathrm{g})$. Fig. 8: rombo $(300 \mu \mathrm{g})$. Fig. 9: sem projeçāo $(300 \mu \mathrm{g})$. (PrP - processo mediano do pigóforo; IX - pigóforo). 

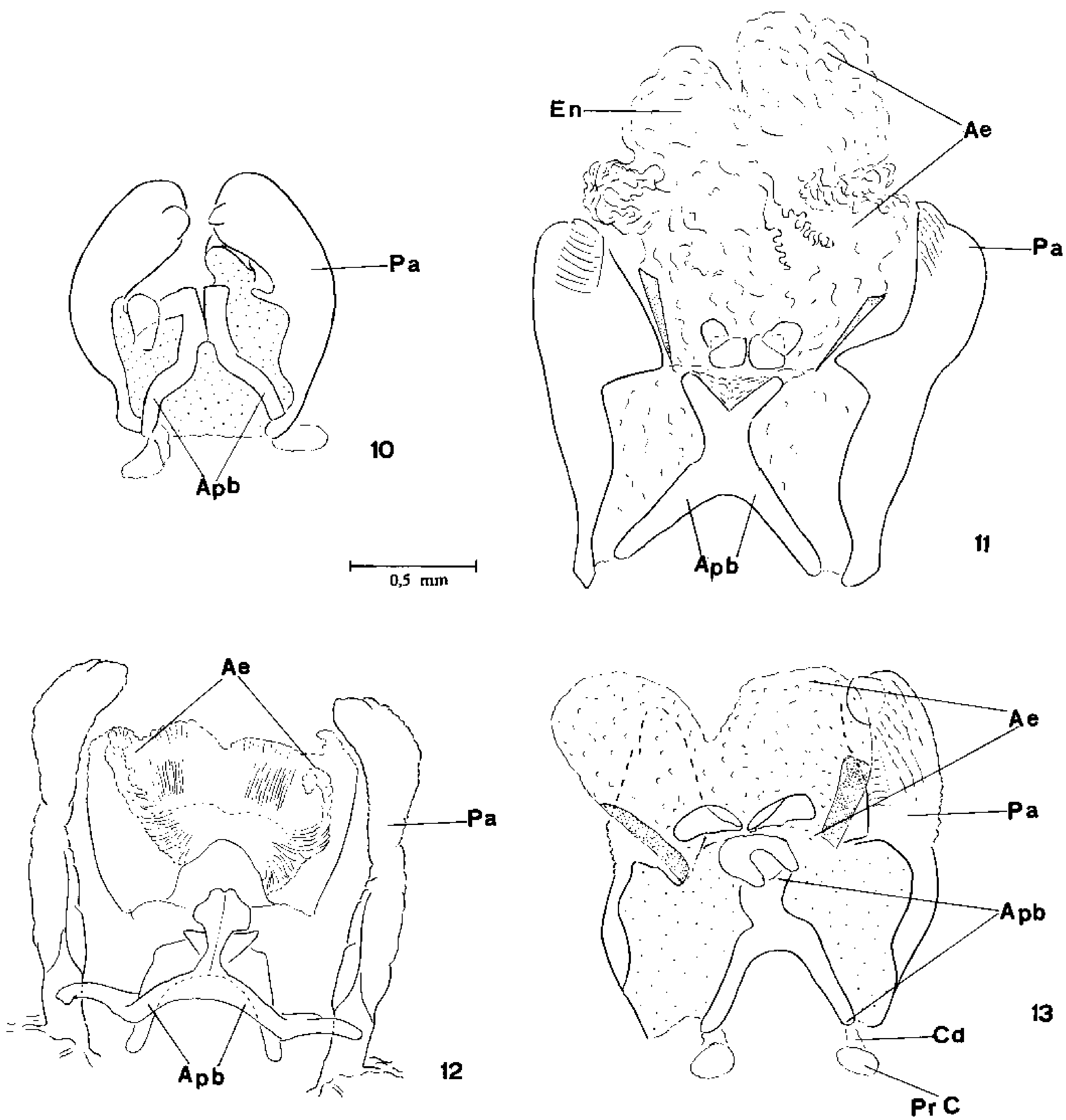

Figs. 10 e 11: falo de um adultóide resultante da aplicação de $300 \mu \mathrm{g}$, vista ventral. Figs. 12 e 13: idem, com aplicação de $400 \mu \mathrm{g}$. 
TABELA I

Medidas comparativas dos tubos testiculares de exemplares normais e tratados com precoceno II

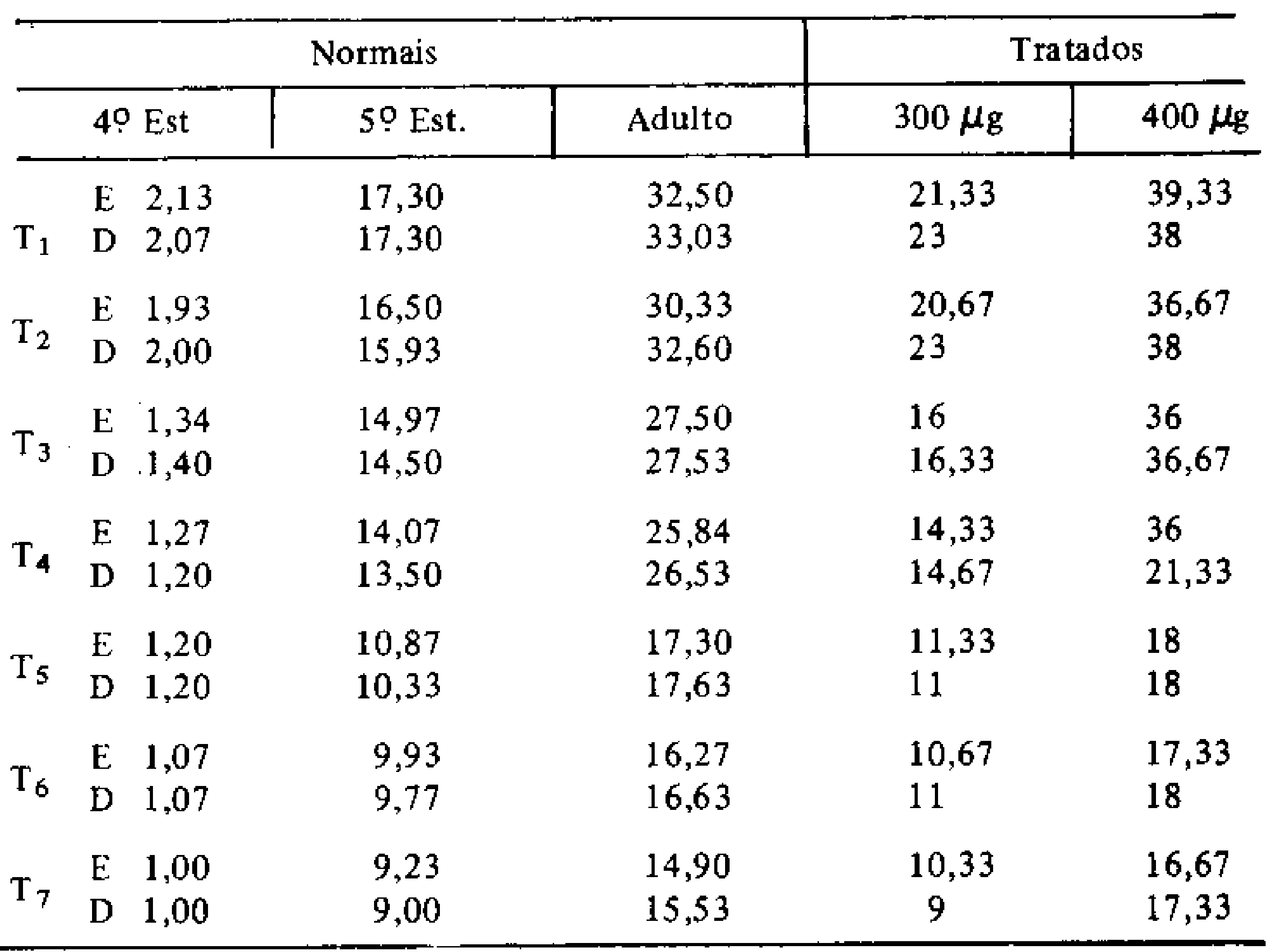

$T=$ tubo testicular $; E=$ esquerdo $; D=$ direito.

Os adultóides resultantes da aplicação de $300 \mu \mathrm{g} / 1 \mu \mathrm{l}$ (Fig. 25) apresentaram os testículos e os tubos testiculares semelhantes à uma ninfa de 5 o estádio normal (Fig. 26). Porém um dos exemplares examinados nāo apresentou as células germinais na luz dos tubos, presentes em nínfas de 5 o estádio normais.

Da aplicação de $400 \mu \mathrm{g} / \mu \mathrm{l}$ um exemplar apresentou os testículos e os tubos testiculares com tamanho intermediário entre as ninfas de 40 e 50 estádios normais, porém neste caso a luz dos tu. bos apresentava uma massa compacta, sem células definidas, semelhantes ao observado na ninfa de 40 estádio normal. O outro exemplar que mudou para o 5 o estádio e posteriormente para adul. to, externamente sem deformações, apresentou os testículos e os tubos testiculares semelhantes à um adulto normal (Fig. 27) (Tab. I).

Biologia - Tanto no grupo controle quanto no grupo em que aplicamos $100 \mu \mathrm{g} / \mu \mathrm{l}$ de precoceno II diluído em acetona não se observou qualquer alteração biológica. Nestes grupos o tempo médio da muda para 5 ọ estádio, a partir da única alimentação no 4 ọ estádio, foi de 13 (mínimo) e 26 dias (máximo). No grupo de $100 \mu \mathrm{g} / \mu \mathrm{l}$ este período variou de 15 (mínimo) a 19 dias (máximo) (Tab. II). Estes insetos alcançaram a fase adulta dentro de um período de 57 dias. Estes resultados são comparáveis aos de Szumlewics (1975) que estudando o ciclo biológico desta espécie em condi. ções controladas de laboratório (alimentação em galinhas e temperatura de 22 a $28^{\circ} \mathrm{C}$ ) observou um mínimo de 22 e máximo de 26 dias para esta espécie no 4 o estádio e um mínimo de 36 e máximo de 66 dias para 5 o estádio.

Nos grupos que receberam dosagens de 200,300 e $400 \mu \mathrm{g}$ e induziram a formação de adultóides, o período de muda foi mais longo e também variável dentro da mesma dosagem: para o grupo de $200 \mu \mathrm{g}$ de precoceno II obteve-se um único adultóide após 159 dias ao tratamento e para os que mudaram aparentemente sem alterações este período foi de 15 (mínimo) e 19 dias (máximo); para o grupo de $300 \mu \mathrm{g}$ o período de intermuda dos adultóides foi de 19 (mínimo) e 30 dias (máximo) e para os aparentemente normais variou de 17 a 19 dias; para $400 \mu \mathrm{g}$ o período da intermuda dos adultóides foi de 38 (mínimo) e 52 dias (máximo) os aparentemente normars em 17 dias (Tab. II). 
TABELA II

Efeitos do precoceno II, aplicado topicamente, em ninfas de 49 estádio de Triatoma infestans, sobre o período de intermuda e induçāo de adultóides

\begin{tabular}{|c|c|c|c|c|c|}
\hline \multirow{2}{*}{$\begin{array}{c}\text { P II } \\
\mu / \text { Inse to }\end{array}$} & \multirow{2}{*}{$\begin{array}{l}\text { No de } \\
\text { Insetos }\end{array}$} & \multirow{2}{*}{$\begin{array}{l}\text { Período de } \\
\text { Intermuda } \\
\text { (Dias após a } \\
\text { Alimentaçāo) }\end{array}$} & \multicolumn{2}{|c|}{$\%$ de Muda } & \multirow{2}{*}{$\begin{array}{c}\% \text { de } \\
\text { lnibição de Muda }\end{array}$} \\
\hline & & & Normais & Adultóides & \\
\hline \multicolumn{6}{|l|}{ controle } \\
\hline $1 \mu \mathrm{l} /$ acetona & 10 & $13-26$ & 100 & 0 & 0 \\
\hline $100 \mu \mathrm{g}$ & 5 & $15-19$ & 80 & 0 & 20 \\
\hline $200 \mu \mathrm{g}$ & 6 & $15-159^{*}$ & 66 & 17 & 17 \\
\hline $300 \mu \mathrm{g}$ & 10 & $17-30$ & 20 & 60 & 20 \\
\hline $400 \mu \mathrm{g}$ & 10 & $17-52$ & 20 & 60 & 20 \\
\hline
\end{tabular}

* Este período foi de um único adultóide obtido nesta dosagem.

TABELA III

Observação da longevidade de adultóides de 5 ọ estádio de Triatoma infestan obtidos por tratamento tópico de precoceno II

\begin{tabular}{l|c|c|c|c}
\hline \multirow{2}{*}{ Dose } & \multirow{2}{*}{$\begin{array}{c}\text { No de } \\
\text { Adultóides }\end{array}$} & \multicolumn{2}{|c|}{$\begin{array}{c}\text { Longevidade } \\
\text { (Dias) }\end{array}$} & $\overline{\mathrm{X}}$ \\
\cline { 3 - 4 } & & Mínimo & Máximo & \\
\hline $200 \mu \mathrm{g}$ & 1 & - & 22 & 22 \\
$300 \mu \mathrm{g}$ & 6 & 14 & 22 & 17,5 \\
$400 \mu \mathrm{g}$ & 6 & 3 & 13 & 8 \\
\hline
\end{tabular}

A percentagem de muda para as diferentes dosagens foi a seguinte: mudas normais $-80 \%$ para $100 \mu \mathrm{g}, 66 \%$ para $200 \mu \mathrm{g}$ e. $20 \%$ para 300 e $400 \mu \mathrm{g}$; mudas alteradas, isto é, que resultaram adultóides $-17 \%$ para $200 \mu \mathrm{g}, 60 \%$ para 300 e $400 \mu \mathrm{g}$.

Observou-se ainda nestes grupos, que alguns insetos sofreram inibição da muda e, após seis meses ao tratamento, não apresentaram qualquer alteração, permanecendo no 4 ?̣ estádio. Durante este período foram oferecidas refeiçōes mensais, nas quais se alimentavam fartamente $e$ ao dissecá-los nāo se evidenciou a formaçāo de uma outra cutícula interna, que indicaria uma nova muda. A percentagem destes insetos foi de $20 \%$ para os grupos de: 100,300 e 400 e de $17 \%$ para 200 (Tab. II).

Quanto ao tempo de vida dos adultóides, observou-se que quanto menor a dosagem, maior foi o período de sobrevivência: para $200 \mu \mathrm{g}$ o único adultóide sot reviveu 22 dias; para $300 \mu \mathrm{g}, 14$ (mínimo) e 22 dias (máximo) e para $400 \mu \mathrm{g}, 3$ (mínimo) e 13 di as (máximo) (Tab. III). A estes adultóides foi oferecida alimentação diária por 10 minutos. Durante este período picavam incessantemente sem se fixar a um determinado local, conseqüentemente sem se alimentar, devido às anomalias do rostro. 

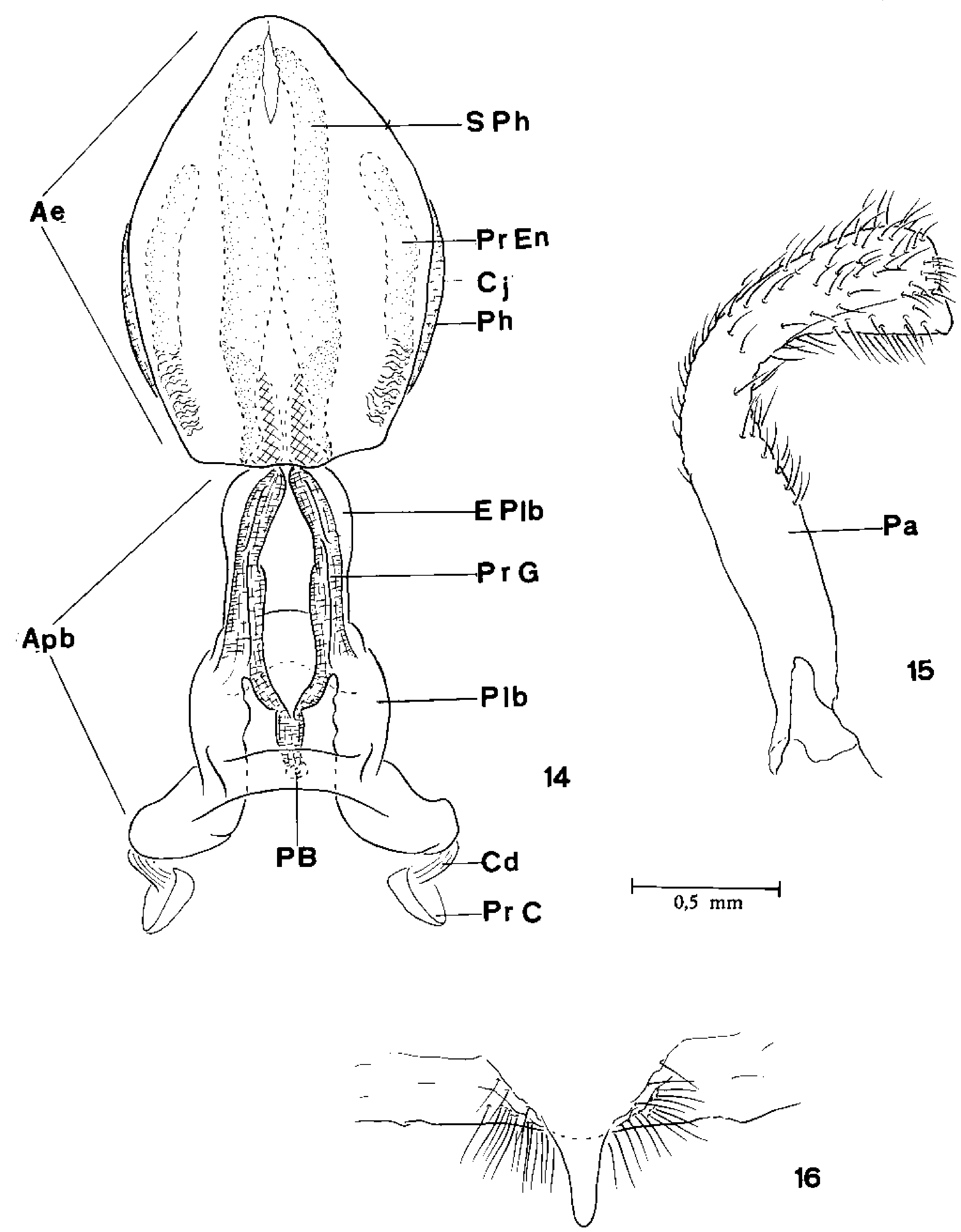

Genitália externa de um adulto normal (macho). Fig. 14: falo, vista ventral. Fig. 15: parâmero, visto de perfil. Fig. 16: processo mediano do pigóforo, vista dorsal. 


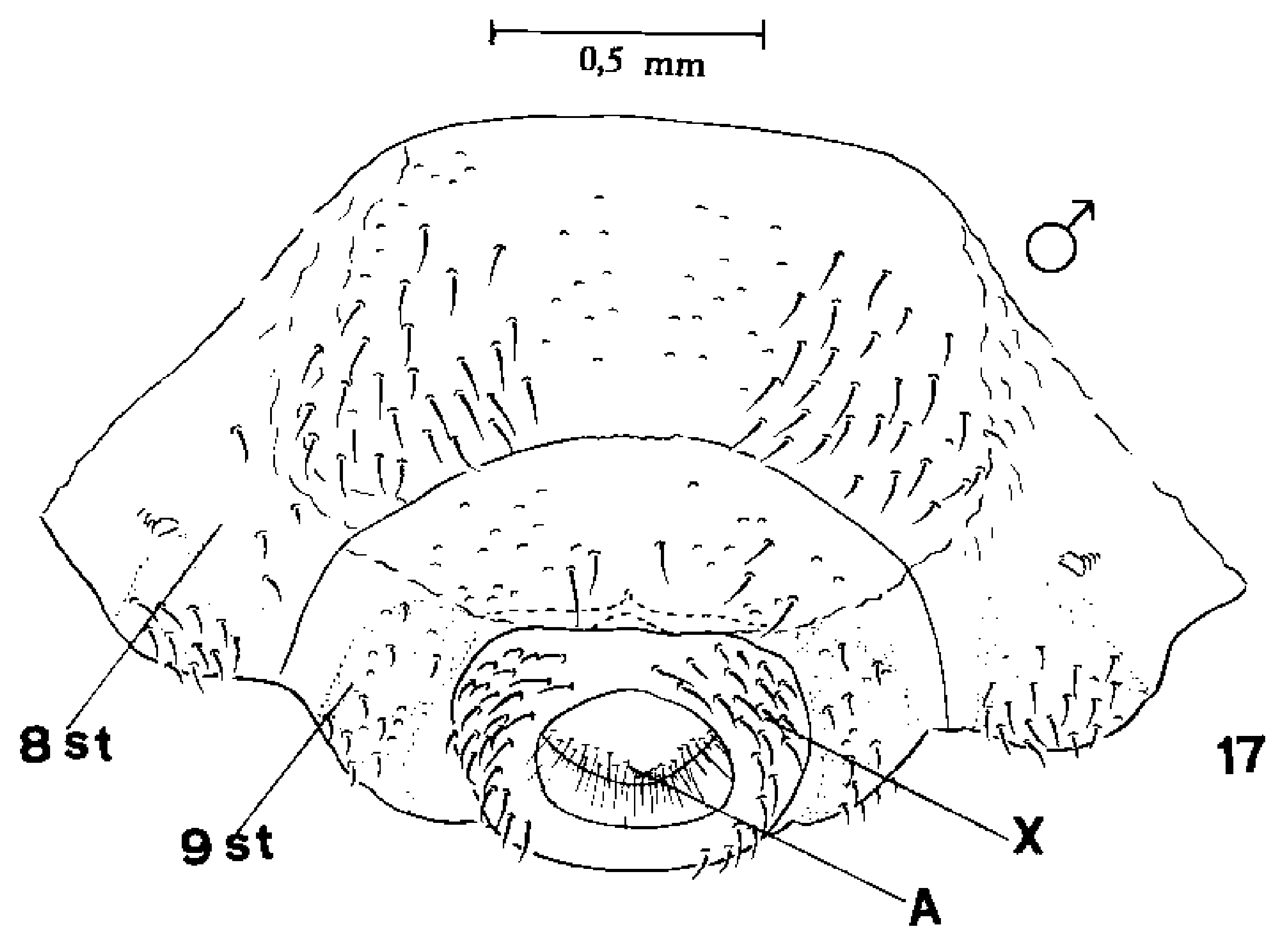

Fig. 17: extremidade posterior de uma ninfa de 5 o estádio normal, vista ventral. (A - ânus; X - 10 o segmento; 8 st -89 estemito; 9 st -9 o estemito).
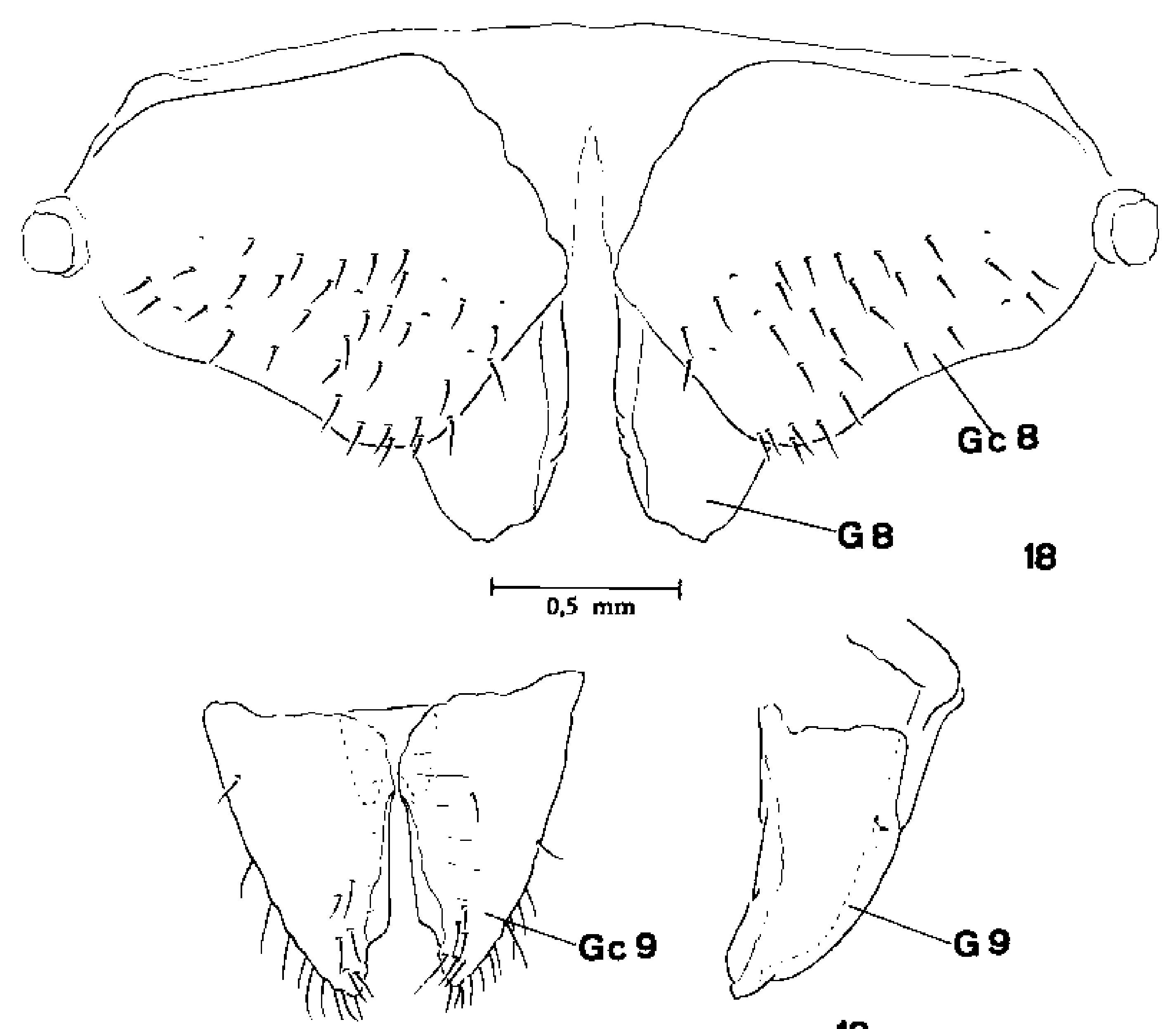

19

Placas genitais de um adultóide resultante da aplicação de $400 \mu \mathrm{g}$. Fig. 18: gonocoxito e gonapófise do 80 segmento. Fig. 19: idem, do 90 segmento. (Gc8 gonocoxito do 8 o segmento: G8 - gonapófise do 8 \% segmento; Gc9 - gonocoxito do 9 o segmento; G9 - gonapófise do 90 segmento). 


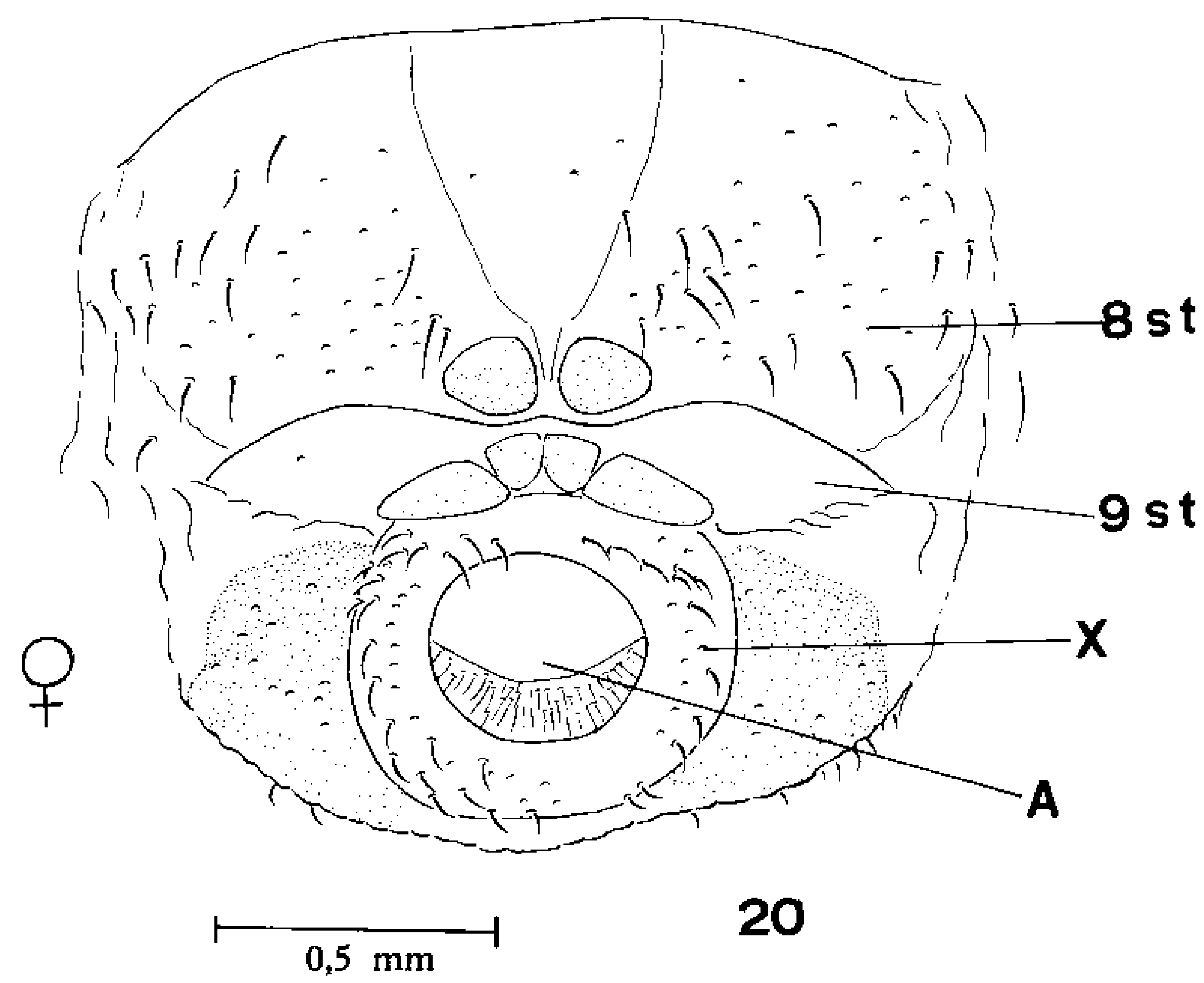

Fig. 20: extremidade posterior de uma ninfa de 5 o estádio normal, vista ventral. (A - ânus; X - 10 o segmento; 8st - 89 estemito; 9st - 90 estemito).
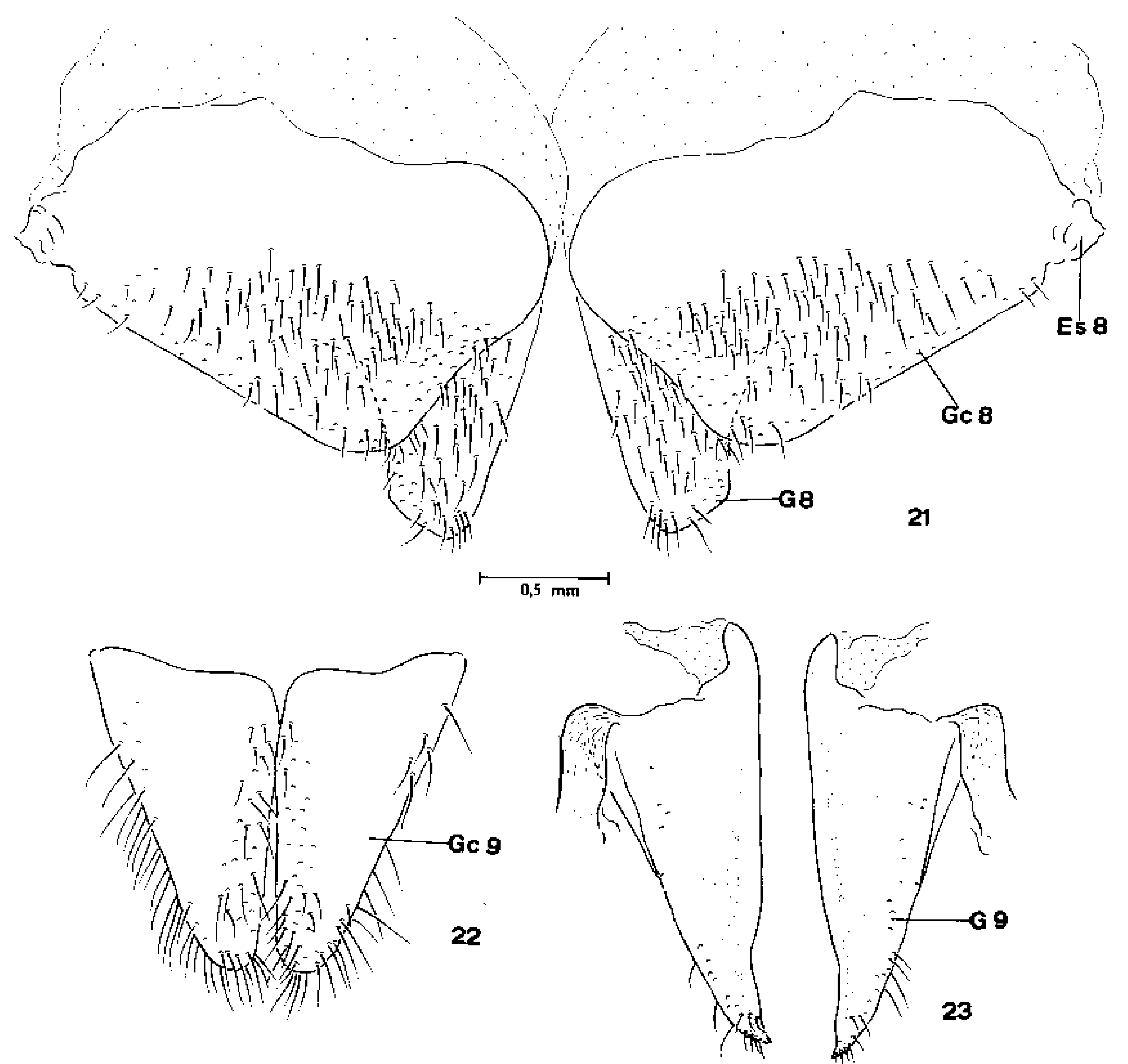

Placas genitais de um adulto normal (fêmea). Fig. 21 : gonocoxito e gonap6fise do 89 segmento. Fig. 22: gonocoxito do 90 segmento. Fig. 23: gonapófise do 9 \% segmento. (Es8 - estigma respiratório; $\mathrm{Gc8}$ - gonocoxito do 8 9 segmento; G8 - gonapofise do 8 9 segmento; $G \mathrm{c} 9$ - gonocoxito do $90^{\circ}$ segmento; $\mathrm{G} 9$ gonapófise do 9 \% segmento). 

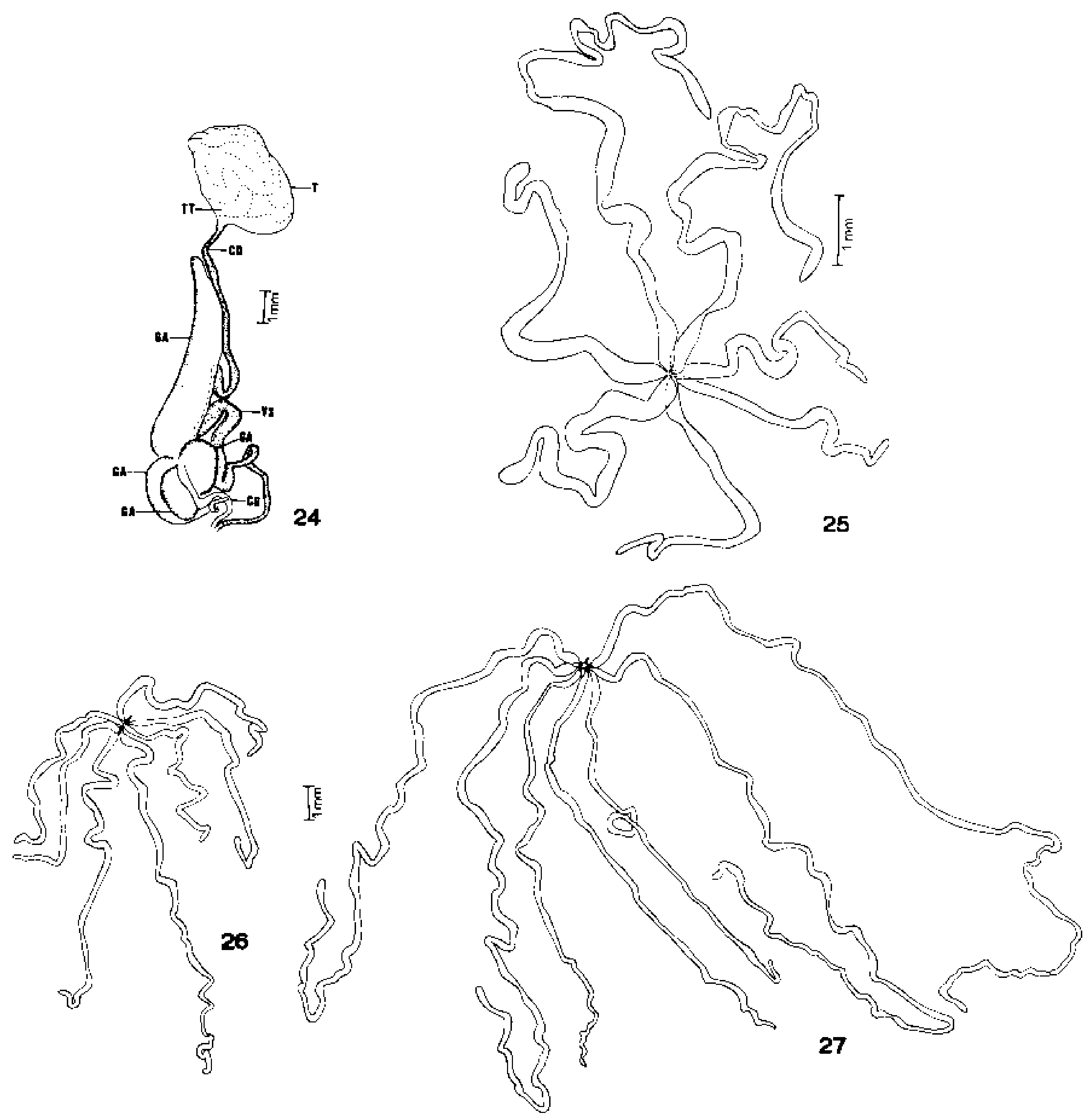

Genitálja interna. Fig. 24 : adulto normal. Fig. 25 : tubos testiculares de um adultóide resultante da aplicação de $300 \mu \mathrm{g}$. Fig. 26: tubos testiculares de uma ninfa de 5 o estádio normal. Fig. 27: tubos testiculares de adulto normal.

\section{CONCLUSÕES}

Susceptibilidade: nas doses de 200,300 e $400 \mu \mathrm{g}$ de precoceno II diluído em $1 \mu \mathrm{l}$ de acetona, por inseto, obtiveram-se três efeitos para cada dose em diferentes percentagens: insetos que aparentemente nâo sofreram ação da substância, isto é, mudaram para uma ninfa normal de 50 o estádio; insetos com características de adultóides; e insetos que após seis meses ao tratamento não haviam realizado a ecdise, com total inibição da muda.

Alterações morfologicas - externas: as dosagens de 200,300 e $400 \mu \mathrm{g} / 1 \mu 1$ induziram o aparecimento de adultóides com deformações no rostro, asas, patas, tegumento e genitália (falo e parâmeros atrofiados e reunidos em uma peça; placas genitais deformadas).

Estas deformações independeram da dosagem da substância ativa aplicada, o que variou foi a percentagem de adultóides resultantes em cada dosagem. Genitália interna: apresentou diferentes tipos de alteraçōes tanto nas dosagens de 300 , quanto em 400 , sendo que nesta última os resultados foram mais acentuados.

Observou-se também que as estruturas internas nāo acompanharam o grau de alteraçōes dos caracteres externos, principalmente da genitália externa. Os adultóides, embora tivessem uma genitália externa próxima de um adulto, a genitália intema apresentou um grau de desenvolvimento intermediário entre uma ninfa de 40 e $50^{\circ}$ estádios.

Ciclo biológico: os adultóides apresentaram um período de intermuda mais longo que os insetos de aparência normal e o período de sobrevivência foi mais longo para aqueles que receberam dosagens mais baixas. 


\section{SUMMARY}

The morphogenetic effect of precocene II on 4th instar nymphs of Triatoma infestans was examined. Topical treatment with precocene II $(200,300$ and $400 \mu \mathrm{g} / \mathrm{nymph})$ induced the formation of adultoids with the following characteristics: rudimentary wings, three segmented tarsi, ocelli, deformed genitalia and mouth-parts and testes with intermediary development.

Precocene II also increases the duration of the molting cycle. The survival of the adultoid insects was related to the inverse of the applied doses. These data extend our knowledge of the action of precocene II on triatominae species.

Key words: precocene II - Triatoma infestans' nymphs - morphological alterations - biological alterations

\section{REFERÊNCIAS BIBLIOGRĀFICAS}

AZAMBUJA, P.D.; BOWERS, W.S.; RIBEIRO, J.M.C. \& GARCIA, E.S., 1982. Antifendant activity of precocenes and anaiogs on Rhodnius prolixus. Experientia, 1054-1055.

AZAMBUJA, P.D.; GARCIA, E.S. \& FURTADO, A.F., 1981. Actions du précocène II sur le retard de la mue et de la metamorphose chez Rhodnius prolixus. C.R. Acad. Sci. Paris, $292: 1173-1175$.

AZ AMBUJA, P.D.; GARCIA, E.S. \& RIBEIRO, J.M.C., 1981. Effects of ecdysone on the metamorphosis and ecdysis prevention of Rhodnius prolixus induced by precocene II. Gen. Comp. Endocrinol., 45:100-104.

BARTH, R., 1956. Estudos anatômicos e histológicos sobre a sub-família Triatominae (Heteroptera, Reduviidae). V Parte: Anatomia do testículo e espermiocitogênese do Triatoma infestans. Mem. Inst. Oswaldo Cruz, 54 (1) :135-189, figs. 1-113.

BOWERS, W.S., 1976. Discovery of insect antiallatotropins. In Gilbert L.1. (ed.): "The juvenile hormones". New York Plenum Press, pp. 394-408.

BOWERS, W.S., 1981. How anti-juvenile hormones work. Ann. Zool., $21: 734-739$.

BOWERS, W.S., 1982 a. Endocrine strategies for insect control. Entomol. Exp. Appl, 31 :3-14.

BOWERS, W.S., 1982b. The precocenes. In: Invertebrate Endocrinology. Downer R.G.H. \& Lanfer, H. (eds.) Han R. Liss, N.Y., pp. 517-523.

BOWERS, W.S.; EVANS, A.H.; MARSELLA, P.A.; SODERLUND, D.M. \& BETTARINI, F., 1982. Natural and synthetic allato toxius: suicide substrates for juvenile biosynthesis. Science, $217: 647-649$.

BOWERS, W.S. \& FELDLAUFER, M.F., 1982. In vitro inactivation of Tenebrio molitor corpora allata by a synthetic precocene analog. Gen. Comp. Endocrinol., $47: 120-126$.

BOWERS, W.S. \& MARTINEZ-PARDO, R., 1977. Antiallatotropins: inhibition of corpus allatum development. Science, $197: 1369-1371$.

BOWERS, W.S.; OHTA, T.; CLEERE, J.S. \& MARSELLA, P.A., 1976. Discovery of insect anti-juvenile hormones in plants. Science, $193: 542-547$.

GARCIA, E.S.; AZAMBUJA, P.D. \& BOWERS, W.S., 1984. Comparison of structurally analogous allatotoxins on the molting and morphogenesis of Rhodnius prolixus and the reversal of ecdysial stasis by ecdysone. Arch. Insect. Biochem. Physiol., $1: 367.373$.

JURBERG, J.; COSTA, JANE, M.; GONÇALVES, T.C.M.; GARCIA, E.S. \& AZAMBUJA, P.D., 1984. Ëfeitos Morfogênicos de Precoceno II em ninfas de Rhodnius prolixus (Stal, 1859) (Hemiptera, Triatominae). Mem. Inst. Oswaldo Cruz, Rio de Janeiro, 79 (4) :397-407.

JURBERG, J.; GONÇALVES, T.C.M. \& OLIVEIRA FILHO, A.M., 1982. Alteraçōes morfológicas provocadas pela aplicação de precoceno II em Panstrongylus megistus. Rev. Bras. Biol., $42: 527.538$.

LENT, H. \& JURBERG, J., 1978. Estudo comparativo da genitália externa masculina de seis espécies de Tria. toma Laporte, 1832 que mais freqüentemente habitam o domicílio humano no Brasil (Hemiptera, Reduvidae). Rev. Bras. Biol., (RJ), 38 (4) :931-944.

LENT, H. \& WYGODZINSKY, 1979. Revision of the Triatominae (Hemiptera, Reduviidae) and their significance as vectors of Chagas' disease. Bull. of the Am. Mus. of Nat. Hist., 163 (3).

LIECHTLY, L. \& SEDLAK, B.J., 1978. Ultrastructure of precocene induced effects on the corpora allata of adult. Oncopeltus fasciatus. Gen. Comp. Endocrinol., 36:433-437.

PRATT, G.E. \& BOWERS, W.S., 1977. Precocene II in hibits juvenile hormone biosynthesis by cockroach corpora allata in vitro. Nature, Lond., $265: 548-551$.

PRATT, G.E.; JENNINGS, R.C.; HAMMET, A.F. \& BROOKS, G.T., 1980. Lethal metabolism of precocene I to a reactive epoxide by Locusta corpora allata. Nature, Lond., $284: 320-323$.

PENER, M.P.; ORSHAN, L. \& DE WILDE, J., 1978. Precocene II causes atrophy of corpora allata in Locusta migratoria. Nature, Lond., $272: 350-353$.

SILVA, F.P. da \& SCHREIBER, G., 1969. Morphology of spermatogenetic tubes as taxonomic character in Triatominae (Reduvidae, Hemiptera). Rev. Brasil. Biol., 29 (1):97-102, figs. 1-2, tab. 1.

SZUMLEWICZ, A.P., 1975. Laboratory colonies of Triatominae, biology and population dynamics. In: American Trypanosomiasis Research. PAHO, Sci. Publ. (318). 
SCHOONEVELD, H., 1979. Precocene-induced collapse and resorption of corpora allata of Locusta migratoria. Experientia, $35: 363-364$.

TARRANT, C.A. \& CUPP, E.W., 1978. Morphogenetic effects of Precocene II on the reproduction and development of Triatominae bugs. Am. J. Trop. Med. Hyg., $31: 416-420$.

TARRANT, C.A.; CUPP, E.W. \& BOWERS, W.S., 1982. The effects of precocene on reproduction and development of Triatominae bugs. Am. J. Trop. Med. Hyg., $31: 416-420$.

UNNITHAN, G.C. \& NAIR, K.K., 1979. The influence of corpus allatum activity on the susceptibility of Oncopeltus fasciatus to precocene. Ann. Entomol. Soc. Am, $72: 3842$.

UNNITHAN, G.C.; NAIR, K.K. \& BOWERS, W.S., 1977. Precocene-induced degeneration of the corpus allatum of adult females of the bug Oncopeltus fasciatus. J. Insect. Physiol., $23: 1081-1094$. 